\title{
A Model for Predicting Post-Stall Behavior of Axial Compressors
}

\author{
M. Shahriyari ${ }^{1}$, H. Khaleghi ${ }^{1 \dagger}$ and M. Heinrich ${ }^{2}$ \\ ${ }^{1}$ Department of Aerospace Engineering, Amirkabir University of Technology, Tehran, Iran \\ ${ }^{2}$ Institute for Mechanics and Fluid Dynamics, Technical University Bergakademie, Freiberg, Germany \\ †Corresponding Author Email: Khaleghi@aut.ac.ir
}

(Received February 16, 2020; accepted October 28, 2020)

\begin{abstract}
The current paper reports on a new theory developed by modifying the basic Moore-Greitzer model, which can predict the performance of a compression system during the instabilities in more details. The general assumptions such as the compression system layout, the lags in the entrance and exit ducts, the compressor axisymmetric characteristic and the small disturbances are similar to those of Moore-Gereitzer model. However, a second order hysteresis is used in the current work for the pressure rise of the rotor and stator rows. As a result, some new parameters are added to the governing equations, such as the stall cell acceleration $\left(d^{2} r / d \xi^{2}\right)$, second derivative of the mean axial flow coefficient $\left(d^{2} \Phi / d \xi^{2}\right)$, second derivative of the disturbance amplitude $\left(d^{2} A / d \xi^{2}\right)$ and slope of the compressor characteristic curve. This gives the modified model new capabilities, like investigating the transient speed of the stall cell or the effect of the throttling rate on the instabilities, which are discussed in details in the current paper.
\end{abstract}

Keywords: Surge; Rotating stall; Compressor characteristic.

\section{NOMENCLATURE}

\begin{tabular}{|c|c|}
\hline$a_{n}, b_{n}$ & Fourier coefficient of $g(\theta)$ and $h(\theta)$ \\
\hline$A$ & $\begin{array}{l}\text { amplitude function of first-harmonic } \\
\text { angular disturbance }\end{array}$ \\
\hline$A_{c}$ & compressor duct area \\
\hline$a$ & $\begin{array}{l}\text { reciprocal time-lag parameter of blade } \\
\text { passage }\end{array}$ \\
\hline$a_{s}$ & sound speed \\
\hline$B$ & Greitzer parameter \\
\hline$F$ & $\begin{array}{l}\text { steady pressure rise coefficient in blade } \\
\text { passage }\end{array}$ \\
\hline$F_{T}$ & throttle characteristic function \\
\hline$f$ & non-dimensional speed coefficient \\
\hline$g$ & disturbance of axial flow coefficient \\
\hline$H$ & $\begin{array}{l}\text { semi-height of cubic axisymmetric } \\
\text { characteristic }\end{array}$ \\
\hline$h$ & circumferential velocity coefficient \\
\hline$K_{G}$ & loss coefficient at IGV entrance \\
\hline$K_{T}$ & throttle coefficient \\
\hline$l_{c}$ & $\begin{array}{l}\text { total aerodynamic length of compressor } \\
\text { and ducts }\end{array}$ \\
\hline$l_{E}$ & length of exit in wheel radii \\
\hline$l_{I}$ & length of entrance in wheel radii \\
\hline$l_{T}$ & length of throttle ducts in wheel radii \\
\hline
\end{tabular}

$m \quad$ parameter defining lag tendency outside compressor

$N \quad$ number of stages of core compressor

$n$ wave number (corresponding to number of stall cells)

$P \quad$ pressure coefficient

$p_{0} \quad$ static pressure at entrance to IGV

$p_{1} \quad$ static pressure at entrance of core compressor

$p_{E} \quad$ static pressure at exit of core compressor

$p_{S} \quad$ static pressure at end of exit duct, and pressure in the plenum

$p_{T} \quad$ total pressure ahead of entrance and following the throttle duct

$R \quad$ mean wheel radius

$r$ time-dependent phase angle

$t \quad$ time

$U \quad$ wheel speed at mean diameter

$V_{P} \quad$ volume of plenum

$W \quad$ semi-width of cubic characteristic

$Y$ disturbance potential at compressor entrance 
$\eta \quad$ axial disturbances measured in wheel radii

$\theta \quad$ angular coordinate around wheel

$\theta^{*} \quad$ angular coordinate around wheel, measured relative to a rotating-stall cell

$\xi \quad$ time, referred to time for wheel to rotate one radian

$\tau \quad$ coefficient of pressure-rise lag

$\Phi$ axial flow coefficient in compressor, annulus averaged; axial velocity divided by wheel speed

$\Phi_{T} \quad$ flow coefficient of throttle duct

$\phi \quad$ local axial flow coefficient, a function of

$\begin{array}{ll} & \theta \text { and } \xi \\ \tilde{\phi} & \text { velocity potential in entrance duct } \\ \tilde{\phi}^{\prime} & \text { disturbance velocity potential } \\ \Psi & \text { total-to-static pressure rise coefficient } \\ \psi_{c} & \text { axisymmetric pressure rise coefficient } \\ \psi_{c 0} & \text { shut-off value of axisymmetric } \\ & \text { characteristic }\end{array}$

\section{SUBSCRIPTS}

0 at the entrance to the compressor

$E \quad$ at the exit of the compressor

\section{INTRODUCTION}

There is always a strong motivation to increase the safe operating range of axial compressors which is limited by the onset of two aerodynamic instabilities, rotating stall and surge. Surge is characterized as large amplitude oscillations of the annulus flow through the whole compression system, whereas rotating stall is a localized disturbance which might be limited to some of the compressor stages. There are two well-known types of stall inception patterns, modal and spike (McDougall et al. (1990) and Day (1993b)). In modal stall inception, long length-scale perturbations gradually buildup and lead to the formation of stall cells. Modal waves might survive 20-200 rotor revolutions prior to rotating stall. This type of stall inception was first predicted theoretically by Moore (1984 I, II) and Moore and Greitzer (1986) before being observed by a number of researchers (e.g., Tryfonidis et al. (1995), Garnier et al. (1991) and Hendricks (1993)). As reported by Garnier et al. (1991) and Hendricks et al. (1993), modal stall inception can occur in high speed compressors as well as low speed ones. Furthermore, it was shown by Hendricks et al. (1993) that compressibility does not have a dominant effect on the dynamic behavior of the stall cells. On the other hand, spike-type stall inception involves a short length-scale disturbance which appears suddenly and develops directly into rotating stall (Camp and Day (1997) and Gong et al. (1999)).

Theoretical and semi-empirical models of surge and rotating stall have been reported by a number of researchers (Moore (1984 I, II), Moore and Greitzer (1986), Emmons (1955), Stenning and Kriebel (1956), Takata and Nagano (1972), Cumpsty and Greitzer (1982)). Emmons (1955) postulated a theory to predict the propagation speed of the stall cell in cascades. Irrotational flow was assumed at the cascade inlet and a transient velocity field (time-averaged axial and tangential velocity components together with small disturbance velocities) was applied. Stenning and Kriebel (1956) also employed small disturbance approach to calculate the stall cell propagation velocity. Takata and Nagano (1972) reported on a nonlinear

analysis of rotating stall, in which blade rows were replaced by semi-actuator disks. A semi-empirical model was presented by Cumpsty and Greitzer (1982), based on an analytical estimate of the pressure change across a stall cell boundary. Moore (1984a, b) developed a model of unsteady pressure rise across a blade passage at in-stall condition. The stall cell was modeled as a small circumferential disturbance to axial and tangential velocities. The disturbances were assumed to be expressed as Fourier series and the propagation velocity of the stall cell was calculated by equating the coefficients of trigonometric functions. A theory was developed by Moore and Greitzer (1986) to model the performance of an axial flow compressor as it leaves stable operation and moves toward instabilities. This model focused on the initial transient period leading to either fully developed rotating stall or surge.

Gong et al. (1991) presented a 3-D computational model for compressor instability which employed a three dimensional distribution of body forces. The model made it possible to simulate both modal and spike stall inception. A three dimensional model based on the body force method and empirical correlations has been developed by Righi et al. (2018). Results showed that the model can simulate rotating stall and surge fairly accurately.

Many numerical investigations concerning rotating stall inception have been reported recently. Vo et al. (2008) introduced two criteria for spike type rotating stall inception. The first condition was that the interface between the tip clearance and oncoming flows becomes parallel to the leadingedge plane, leading to the occurrence of the leading-edge vortex spillage. The second condition was the initiation of reverse flow at the trailingedge plane. Similar findings were reported for highspeed compressors (e.g., Chen et al. (2008), Choi et al. (2011) and Khaleghi (2015)). In the experiments reported by Weichert and Day (2013), however, no spillage was observed before and during the emergence of spike. As emphasized by Weichert and Day (2013), the debate about whether forward spillage occurs before or after stall onset is a topic of current interest which requires more numerical and experimental investigations.

Epstein et al. (1989) was the first who suggested 
the concept of the so called intelligent engines, in which stalling disturbances are detected and suppressed at early stages of formation (e.g., Day (1993a) and Paduano et al. (1991)). Since then Moore-Greitzer model has become a theoretical framework for active control of instabilities in compression systems. However, there are some drawbacks in the basic Moore-Greitzer model, one of which is that it does not include the slope of the compressor characteristic curve (it is assumed that stall is initiated at peak pressure rise where the slope of the compressor characteristic is zero). However, Camp and Day (1997) showed that the slope of the compressor total to static pressure rise characteristic for modal stall inception can be between roughly -0.2 to +0.2 . Furthermore, the basic Moore-Greitzer method can not model the transient behavior of the stall cells. The main objective of the current work is to develop a modified model based on the basic Moore-Greitzer method with more capabilities and advantages such as modeling the stall cell transient behavior and including the slope of the compressor characteristic curve for low-speed axial compressor.

\section{Modeling}

\subsection{Compressor Model}

The compression system is assumed to be the same as that modeled by Moore and Greitzer (1986) (Fig. 1 in Moore and Greitzer (1986)). The compressor is assumed to have high hub-to-tip radius ratio blades, which enables 2-D flow assumption. The inlet and outlet channels as well as the compressor are assumed to have constant cross sections. The flow is assumed to be incompressible, frictionless and irrotational within the entrance duct. It is further assumed that the flow is inviscid throughout the whole compression system and also is compressible everywhere, except in the plenum chamber. The circumferential coordinate is denoted by the wheel angle $\theta$ and the axial coordinate by the nondimensional parameter $\eta$ (the axial distance divided by the compressor mean radius). Furthermore, the non-dimensional time is defined as:

$$
\xi=U t / R
$$

The axial flow coefficient is postulated to be consisted of a mean value and a small axial disturbance (Eq. (2)). This axial disturbance term is not only a function of the circumferential coordinate but also a function of time, in order to enable transient behavior of the compression system during surge or stall.

$\phi=\Phi(\xi)+g(\xi, \theta)$

The mean axial flow coefficient $(\Phi(\xi))$ is defined as:

$$
\frac{1}{2 \pi} \int_{0}^{2 \pi} \phi(\xi, \theta) d \theta=\Phi(\xi)
$$

A circumferential disturbance is necessary to satisfy the continuity:

$$
h=h(\xi, \theta)
$$

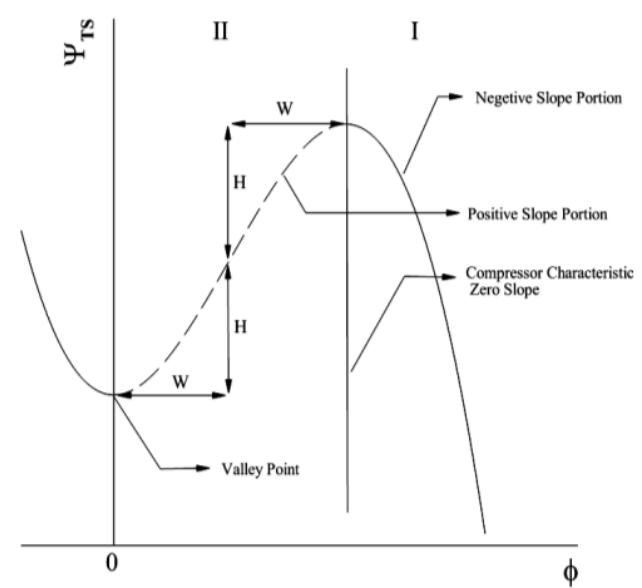

Fig. 1. Compressor axisymmetric characteristic.

As mentioned above, $\Phi$ is the circumferential average of $\phi$, and therefore, the angle average of $g$ must be vanished. Furthermore, due to the irrotational assumption at the entrance of the compressor, the angle average of the circumferential disturbance $(h)$ must be vanished:

$\int_{0}^{2 \pi} g(\xi, \theta) d \theta=0 ; \quad \int_{0}^{2 \pi} h(\xi, \theta) d \theta=0$

In the recent work done by Khaleghi et al. (2020) and Shahriyari et al. (2019), the compressor pressure rise function which was used by Moore (1984a) and Moore and Greitzer (1986) was modified to include a second order derivative term, which enabled the investigation of the stall cell transient behavior. The same hypothesized function is used in the current study:

$\frac{\Delta p}{\frac{1}{2} \rho U^{2}}=F(\phi)-\tau\left(\frac{d \phi}{d t}+\frac{d^{2} \phi}{d t^{2}}\right)$

The terms $d \phi / d t$ and $d^{2} \phi / d t^{2}$ for the rotor and stator can be expressed as follows:

$\left(\frac{d \phi}{d t}\right)_{\text {stator }}=\frac{U}{R} \frac{\partial \phi}{\partial \xi}$

$\left(\frac{d \phi}{d t}\right)_{\text {rotor }}=\frac{U}{R}\left(\frac{\partial \phi}{\partial \xi}+\frac{\partial \phi}{\partial \theta}\right)$

$\left(\frac{d^{2} \phi}{d t^{2}}\right)_{\text {stator }}=\left(\frac{U}{R}\right)^{2} \frac{\partial^{2} \phi}{\partial \xi^{2}}$

$\left(\frac{d^{2} \phi}{d t^{2}}\right)_{\text {rotor }}=\left(\frac{U}{R}\right)^{2}\left(\frac{\partial^{2} \phi}{\partial \xi^{2}}+2 \frac{\partial^{2} \phi}{\partial \xi \partial \theta}+\frac{\partial^{2} \phi}{\partial \theta^{2}}\right)$

By putting Eqs. (7-10) into Eq. (6) and applying the same model for all of the stages, the pressure rise coefficient for the $\mathrm{N}$-stage compressor becomes: 


$$
\begin{aligned}
& \frac{p_{E}-p_{1}}{\rho U^{2}}=N F(\phi)-\frac{1}{2 a}\left(2 \frac{\partial \phi}{\partial \xi}+\frac{\partial \phi}{\partial \theta}\right) \\
& -\frac{1}{2 a}\left[\frac{U}{R}\left(2 \frac{\partial^{2} \phi}{\partial \xi^{2}}+2 \frac{\partial^{2} \phi}{\partial \xi \partial \theta}+\frac{\partial^{2} \phi}{\partial \theta^{2}}\right)\right] \\
& a=\frac{R}{N \tau U}
\end{aligned}
$$

\subsection{Inlet Guide Vanes}

Similar to Moore and Greitzer (1986) and using the same assumptions, the pressure rise through the inlet guide vanes can be modeled as:

$$
\frac{p_{1}-p_{0}}{\rho U^{2}}=\frac{1}{2} K_{G} h^{2}
$$

Where the term $K_{G} h^{2}$ is the coefficient of abrupt pressure rise at the IGV entrance. Note that if the IGV has no loss, the value of $K_{G}$ will be equivalent to one, and otherwise, less than one.

\subsection{Entrance Duct}

The flow in the entrance duct is assumed to be inviscid, incompressible and irrotational, and therefore, Laplace Equation can be used. A velocity potential function $(\tilde{\phi})$ is defined, the derivatives of which gives the axial flow coefficient $(\phi)$ and the circumferential disturbance (h):

$$
\left(\tilde{\phi}_{\eta}\right)_{0}=\Phi(\xi)+g(\xi, \theta) ; \quad\left(\tilde{\phi}_{\theta}\right)_{0}=h(\xi, \theta)
$$

The velocity potential function is defined by Eq. (15) so that it satisfies the condition that $\tilde{\phi}$ be equal to zero at the entrance of the compression system (reservoir).

$$
\tilde{\phi}=\left(\eta+l_{I}\right) \Phi(\xi)+\tilde{\phi}^{\prime}(\xi, \eta)
$$

In order to determine $\tilde{\phi}$, the velocity potential function for the disturbances $\left(\tilde{\phi}^{\prime}\right)$ must be defined, which is given by Eq. (17) (it satisfies the Laplace equation given in Eq. (16)). The derivatives of this Equation in the directions of $\eta$ and $\theta$ at the compressor face are equal to $\mathrm{g}$ and $\mathrm{h}$, respectively. Furthermore, note that this velocity potential function is vanished at far upstream.

$\tilde{\phi}_{\theta \theta}^{\prime}+\tilde{\phi}_{\eta \eta}^{\prime}=0$

$\tilde{\phi}^{\prime}=\sum_{n=1}^{\infty} \frac{1}{n} e^{n \eta}\left(a_{n} \sin n \theta+b_{n} \cos n \theta\right), \quad \eta \leq 0$

By applying the Bernoulli Equation between far upstream and the compressor face (See Moore and Greitzer (1986)).

$$
\frac{p_{T}-p_{0}}{\rho U^{2}}=\frac{1}{2}\left(\phi^{2}+h^{2}\right)+\left(\tilde{\phi}_{\xi}\right)_{0}
$$

Where:

$$
\left(\tilde{\phi}_{\xi}\right)_{0}=l_{I} \frac{d \Phi}{d \xi}+\left(\phi_{\xi}^{\prime}\right)_{0}
$$

\subsection{Outlet Guide Vanes and Exit Duct}

The pressure rise of the OGV and exit duct can be modeled as follows (see Eqs. (17-20) in Moore and Greitzer (1986)):

$$
\frac{p_{S}-p_{E}}{\rho U^{2}}=\left(P_{E}\right)=-l_{E} \frac{d \Phi}{d \xi}-(m-1)\left(\tilde{\phi}_{\xi}^{\prime}\right)_{0}
$$

Where $\mathrm{m}$ is the compressor lag parameter and its value is between one and two (see Moore (1984a)).

\subsection{Pressure Rise through the Compression System}

By using Eqs. (11), (13), (19) and (20), the overall pressure rise through the compressor becomes as follows:

$$
\begin{aligned}
& \frac{p_{S}-p_{T}}{\rho U^{2}}=\left(N F-\frac{1}{2} \phi^{2}\right)- \\
& \left(l_{I}+\frac{1}{a}+l_{E}\right) \frac{d \Phi}{d \xi}-\frac{U}{R a} \frac{d^{2} \Phi}{d \xi^{2}}-m\left(\tilde{\phi}_{\xi}^{\prime}\right)_{0} \\
& -\frac{1}{2 a}\left(2 \tilde{\phi}_{\xi \eta}^{\prime}+\tilde{\phi}_{\theta \eta}^{\prime}\right)_{0}-\frac{1}{2}\left(1-K_{G}\right) h^{2} \\
& -\frac{1}{2 a}\left[2 \tilde{\phi}_{\xi \eta}^{\prime}+\tilde{\phi}_{\theta \eta}^{\prime}+\frac{U}{R}\left(2 \tilde{\phi}_{\xi \xi \eta}^{\prime}+2 \tilde{\phi}_{\xi \theta \eta}^{\prime}+\tilde{\phi}_{\theta \theta \eta}^{\prime}\right)\right]
\end{aligned}
$$

From the definitions of the upstream total to downstream static pressure rise coefficient $(\Psi(\xi)$ given in Eq. (22)), the axisymmetric compressor characteristic $\left(\psi_{c}(\phi)\right.$ given in Eq. (23)) and the compressor non-dimensional effective length (given in Eq. (24)), Eq. (25) can be obtained. It should be noted that the IGV is assumed to have no $\operatorname{loss}\left(K_{G}=1\right)$.

$$
\begin{aligned}
& \Psi(\xi) \equiv \frac{p_{S}-p_{T}}{\rho U^{2}} \\
& \psi_{C}(\phi)=N F-\frac{1}{2} \phi^{2} \\
& l_{c}=l_{I}+\frac{1}{a}+l_{E}
\end{aligned}
$$

$\Psi(\xi)=\psi_{c}\left(\Phi+\left(\tilde{\phi}_{\eta}^{\prime}\right)_{0}\right)-l_{c} \frac{d \Phi}{d \xi}-\frac{U}{R a} \frac{d^{2} \Phi}{d \xi^{2}}$

$-m\left(\tilde{\phi}_{\xi}^{\prime}\right)_{0}-\frac{1}{2 a}\left(2 \tilde{\phi}_{\xi \eta}^{\prime}+\tilde{\phi}_{\theta \eta}^{\prime}\right)_{0}$

$-\frac{1}{2 a}\left[2 \tilde{\phi}_{\xi \eta}^{\prime}+\tilde{\phi}_{\theta \eta}^{\prime}+\frac{U}{R}\left(2 \tilde{\phi}_{\xi \xi \eta}^{\prime}+2 \tilde{\phi}_{\xi \theta \eta}^{\prime}+\tilde{\phi}_{\theta \theta \eta}^{\prime}\right)\right]$

As Eq. (5) indicated, the circumferential average of the disturbance functions ( $g$ and $h$ which are assumed to be periodic) are vanished over 0 to $2 \pi$. By taking the first term of the Fourier series given in Eq. (17), the following equation is obtained:

$\left(\tilde{\phi}_{\eta}^{\prime}\right)_{0}=-\left(\tilde{\phi}_{\theta \theta}^{\prime}\right)_{0}$ 
The function $Y$ is define as follows for the sake of simplicity (see Eqs. (31) to (35) in Moore and Greitzer (1986)):

$h=Y_{\theta} ; \quad g=-Y_{\theta \theta}$

It should be noted that $Y$ is periodic $(Y(\xi, \theta+2 \pi)=Y(\xi, \theta))$ and because the cyclic integral of $\mathrm{g}$ and $\mathrm{h}$ are vanished, the cyclic integral of $Y$ must be vanished as well:

$\int_{0}^{2 \pi} Y(\xi, \theta) d \theta=0$

By using Eq. (27), Eq. (25) become as follows:

$$
\begin{aligned}
& \Psi(\xi)=\psi_{c}\left(\Phi-Y_{\theta \theta}\right)-l_{c} \frac{d \Phi}{d \xi}-\frac{U}{R a} \frac{d^{2} \Phi}{d \xi^{2}} \\
& -m Y_{\xi}+\frac{1}{2 a}\left(2 Y_{\xi \theta \theta}+Y_{\theta \theta \theta}\right) \\
& +\frac{U}{2 R a}\left[2 Y_{\xi \xi \theta \theta}+2 Y_{\xi \theta \theta \theta}+Y_{\theta \theta \theta \theta}\right]
\end{aligned}
$$

\subsection{Overall Pressure Balance}

The continuity equation of the plenum chamber under assumptions of one dimensional and inviscid flow leads to the following equation (Moore and Greitzer (1986)).

$l_{c} \frac{d \Psi}{d \xi}=\frac{1}{4 B^{2}}\left[\Phi(\xi)-\Phi_{T}(\xi)\right]$

In this equation $B$ is the Greitzer parameter:

$$
B \equiv \frac{U}{2 a_{S}} \sqrt{\frac{V_{P}}{A_{c} l_{c}}}
$$

Where $a_{s}$ is the speed of sound, $V_{P}$ is the plenum volume and $A_{c}$ is the compressor cross sectional area.

$$
F_{T}=\frac{1}{2} K_{T} \Phi_{T}^{2}
$$

Where $F_{T}$ is the throttle characteristic function and $K_{T}$ is the throttle coefficient.

One more equation is needed to be solved together with Eqs. (29) and (30) in order to find the unknowns: $\Psi(\xi), \quad \Phi(\xi)$ and $Y(\xi, \theta)$. This equation is obtained by integrating Eq. (29) with respect to $\theta$ and using Eq. (28):

$$
\begin{aligned}
& \Psi(\xi)+l_{c} \frac{d \Phi}{d \xi}+\frac{U}{R a} \frac{d^{2} \Phi}{d \xi^{2}}= \\
& \frac{1}{2 \pi} \int_{0}^{2 \pi} \Psi_{C}\left(\Phi-Y_{\theta \theta}\right) d \theta
\end{aligned}
$$

For pure rotating stall, the time derivatives in the above Equations vanish. By applying the change of variable given in Eq. (34), the governing equations for pure rotating stall become as given in Eqs. (35) to (37). Note that the frame of reference attached to the stall cell is inertia due to the fully developed stall assumption.

$$
\begin{aligned}
& Y(\xi, \theta)=Y\left(\theta^{*}\right), \text { where } \theta^{*}=\theta-f \xi \\
& \frac{U}{2 R a}\left(2 f^{2}-2 f+1\right) \frac{d^{4} Y}{d \theta^{*^{4}}}+ \\
& \frac{1}{2 a}(-2 f+1) \frac{d^{3} Y}{d \theta^{*^{3}}} \\
& +m f \frac{d Y}{d \theta^{*}}=\left[\Psi-\psi_{c}\left(\Phi-\frac{d^{2} Y}{d \theta^{*^{2}}}\right)\right] \\
& \Psi=\frac{1}{2 \pi} \int_{0}^{2 \pi} \Psi_{C}\left(\Phi-\frac{d^{2} Y}{d \theta^{* 2}}\right) d \theta^{*} \\
& \Phi=\Phi_{T}
\end{aligned}
$$

Equation 37 shows that the operating point in pure rotating stall should be on the throttle characteristic curve. Furthermore, note that $d Y / d \theta^{*}=h$ and $d^{2} Y / d \theta^{*^{2}}=-g . \quad$ By $\quad$ approximating $\psi_{c}\left(\Phi-d^{2} Y / d \theta^{*^{2}}\right)$ by the first two terms of its Taylor series (noting that modal waves can be well described by a linear theory Gong (1999)) and representing $\mathrm{g}$ and $\mathrm{h}$ by Fourier series and taking the first term (so that $d h / d \theta=-g$ similar to Moore (1984a)), Eq. (35) becomes:

$$
\begin{aligned}
& \frac{U}{2 R a}\left(2 f^{2}-2 f+1\right)=-\psi_{c}^{\prime} \\
& f=\frac{1 / 2}{1+a m}
\end{aligned}
$$

By putting Eq. (39) into Eq. (38) the following result is obtained (this equation is valid for the negative slope portion of the compressor characteristic where the parameter $a$ is negative (see Fig. 1) :

$\psi_{c}^{\prime}=\frac{-U}{2 R a} Z$

In the positive slope part of the characteristic, $a$ is positive and the following equation can be written:

$\psi_{c}^{\prime}=\frac{U}{2 R a} Z$

Where $\mathrm{Z}$ is defined for convenience as:

$Z=\left(1-\frac{a m+1 / 2}{(1+a m)^{2}}\right)$

By putting Eq. (40) into Eqs. (29) and (33) (Eq. (40(a)) or (40(b)) depending on the operating point), the following equations are obtained (the upper signs in these equations refer to the negative 
and the lower ones to the positive part of the compressor characteristic):

$$
\begin{aligned}
& \Psi(\xi)+l_{c} \frac{d \Phi}{d \xi} \mp \frac{2 \psi_{c}^{\prime}}{Z} \frac{d^{2} \Phi}{d \xi^{2}}=\psi_{c}\left(\Phi-Y_{\theta \theta}\right) \\
& -m Y_{\xi}+\frac{1}{2 a}\left(2 Y_{\xi \theta \theta}+Y_{\theta \theta \theta}\right) \\
& \mp \frac{\psi_{c}^{\prime}}{Z}\left[2 Y_{\xi \xi \theta \theta}+2 Y_{\xi \theta \theta \theta}+Y_{\theta \theta \theta \theta}\right] \\
& \Psi(\xi)+l_{c} \frac{d \Phi}{d \xi} \mp \frac{2 \psi_{c}^{\prime}}{Z} \frac{d^{2} \Phi}{d \xi^{2}}= \\
& \frac{1}{2 \pi} \int_{0}^{2 \pi} \Psi_{c}\left(\Phi-Y_{\theta \theta}\right) d \theta \\
& l_{c} \frac{d \Psi}{d \xi}=\frac{1}{4 B^{2}}\left[\Phi(\xi)-F_{T}^{-1}(\xi)\right]
\end{aligned}
$$

The three equations derived so far are the momentum of the compression system, the annulus averaged momentum balance and the mass balance of the plenum chamber (Eqs. (42-44)). These equations can be compared to Eqs. (42-44) in Moore and Greitzer (1986). Equation (44) (mass balance of the plenum chamber) is the same as its counterpart in Moore and Greitzer (1986). However, as compared to the basic Moore-Greitzer equations, four terms are added to Eq. (42) and one term to Eq. (43), all of which include the slope of the compressor axisymmetric characteristic $\left(\psi_{c}^{\prime}\right)$. In order to solve the above equations, an axisymmetric characteristic function $\left(\psi_{c}(\phi)\right)$ should be determined for the compressor. The same characteristic function used by Moore and Greitzer (1986) is used in the current study to enable comparison with the basic Moore-Greitzer model (Fig. 1):

$$
\psi_{c}(\phi)=\psi_{c 0}+H\left[1+\frac{3}{2}\left(\frac{\phi}{W}-1\right)-\frac{1}{2}\left(\frac{\phi}{W}-1\right)^{3}\right]
$$

Similar to Moore and Gretzier (1986), Galerkin method is used in the current study to solve the above nonlinear equations. The following function is used to represent $\mathrm{Y}$ :

$$
Y=W A(\xi) \sin (\theta-r(\xi))
$$

Where $A(\xi)$ is the unknown amplitude of the disturbances and $r(\xi)$ is the unknown phase angle (which identifies the variation in angular location of the disturbances). By putting Eq. (46) into Eqs. (42) and (43) and then applying the Galerkin method, the following results are obtained:

$$
\begin{aligned}
& \frac{1}{2 \pi} \int_{0}^{2 \pi} \psi_{C}(\Phi+W A \sin \xi) d \xi= \\
& \Psi+l_{c} \frac{d \Phi}{d \xi} \mp \frac{2 \psi_{c}^{\prime}}{Z} \frac{d^{2} \Phi}{d \xi^{2}}
\end{aligned}
$$

$$
\begin{aligned}
& \frac{1}{\pi W} \int_{0}^{2 \pi} \sin \xi \psi_{C}(\Phi+W A \sin \xi) d \xi= \\
& \mp \frac{2 \psi_{c}^{\prime}}{Z} \frac{d^{2} A}{d \xi^{2}}+\left(m+\frac{1}{a}\right) \frac{d A}{d \xi} \\
& +\left( \pm \frac{2 \psi_{c}^{\prime}}{Z}\left(\frac{d r}{d \xi}\right)^{2} \mp \frac{2 \psi_{c}^{\prime}}{Z} \frac{d r}{d \xi} \pm \frac{\psi_{c}^{\prime}}{Z}\right) A \\
& \frac{1}{\pi W} \int_{0}^{2 \pi} \cos \xi \psi_{C}(\Phi+W A \sin \xi) d \xi= \\
& \pm \frac{2 \psi_{c}^{\prime}}{Z} A \frac{d^{2} r}{d \xi^{2}}+\left( \pm \frac{4 \psi_{c}^{\prime}}{Z} \frac{d A}{d \xi}-m A-\frac{1}{a} A\right) \frac{d r}{d \xi} \\
& +\left(\frac{1}{2 a} A \mp \frac{2 \psi_{c}^{\prime}}{Z} \frac{d A}{d \xi}\right)
\end{aligned}
$$

Note that the integral on the left hand side of Eq. (49) becomes zero over a cycle. Unlike the basic Moore-Greitzer, $(d r / d \xi)$ is not constant in the current model.

By using Eq. (45) as the axisymmetric characteristic function of the compressor, the final governing equations are obtained:

$\frac{d \Psi}{d \xi}=\frac{W / H}{4 B^{2}}\left[\frac{\Phi}{W}-\frac{1}{W} F_{T}^{-1}(\Psi)\right] \frac{H}{l_{C}}$

$\mp \frac{2 \psi_{c}^{\prime}}{Z} \frac{d^{2} \Phi}{d \xi^{2}}+l_{c} \frac{d \Phi}{d \xi}=$

$\left[\begin{array}{l}-\frac{\Psi-\psi_{C 0}}{H}+1+\frac{3}{2}\left(\frac{\Phi}{W}-1\right)\left(1-\frac{1}{2} A^{2}\right) \\ -\frac{1}{2}\left(\frac{\Phi}{W}-1\right)^{3}\end{array}\right] H$

$\mp \frac{2 \psi_{c}^{\prime}}{Z} \frac{d^{2} A}{d \xi^{2}}+\left(m+\frac{1}{a}\right) \frac{d A}{d \xi}+$

$\left( \pm \frac{2 \psi_{c}^{\prime}}{Z}\left(\frac{d r}{d \xi}\right)^{2} \mp \frac{2 \psi_{c}^{\prime}}{Z} \frac{d r}{d \xi} \pm \frac{\psi_{c}^{\prime}}{Z}\right) A=$

$\frac{3}{2} \frac{A H}{W}\left[1-\left(\frac{\Phi}{W}-1\right)^{2}-\frac{1}{4} A^{2}\right]$

$\pm \frac{2 \psi_{c}^{\prime}}{Z} A \frac{d^{2} r}{d \xi^{2}}+\left( \pm \frac{4 \psi_{c}^{\prime}}{Z} \frac{d A}{d \xi}-m A-\frac{1}{a} A\right) \frac{d r}{d \xi}$

$+\left(\frac{1}{2 a} A \mp \frac{2 \psi_{c}^{\prime}}{Z} \frac{d A}{d \xi}\right)=0$

Equations (50) to (53) are the governing equations which are coupled and should be solved to give $\Phi$ (circumferentially average flow coefficient), $\Psi$ (total-to-static pressure rise), A (amplitude of angular disturbances) and $r$ (phase angle of disturbances) as a function of $\xi$ (the nondimensional time).

The following parameters affect the compressor response during instabilities: the characteristic 
steepness $(W / H)$, shut-off head $\left(\psi_{c_{0}} / H\right)$, compressor non-dimensional length $\left(l_{c}\right)$, compressor external lag $(m)$, Greitzer parameter ( $B)$, throttle characteristic function $\left(F_{T}(\Phi)\right.$ ) and the slope of the compressor axisymmetric characteristic $\left(\psi_{c}^{\prime}\right)$. One of the advantages of the current model is that it includes the slope of the compressor total to static pressure rise characteristic. The basic Moore-Greitzer equations do not include this parameter. However, if $\psi_{c}^{\prime}=0$ the current model is reduced to the basic MooreGreitzer model (in that case, Eq. (53) decouples from Eqs. (50-52)). Another advantage of the current model is that it enables the investigation of the stall cell transient behavior, because Eqs. (50) to (53) include $d^{2} r / d \xi^{2}$ (stall cell acceleration). Furthermore, $d^{2} A / d \xi^{2}$ and $d^{2} \Phi / d \xi^{2}$ have appeared in the equations. For reference, the relevant parameters through this paper are: $m=1.75, H=0.18, W=0.25,1 / a=3.5, l_{c}=8$.

Finally, in order to solve the differential equations (Eqs (50) to (53)), Runge-Kutta method is used.

\section{VALIDATION}

The ability of the modified model developed in the current study in predicting the transient stall cell speed has been approved by comparing the experimental results reported by Jackson (1986) to the theory in Fig. 2, obtained by solving Eq. (52) and (53). The compressor specifications are given in Table 1. The outside lag parameter $(m)$ has been chosen to be equivalent to 2 (see Moore (1984a)). The time lag parameter $(a)$ was then calculated to be equivalent to 0.4889 . Finally, the initial conditions imposed are: $d \Phi / d \xi(0)=0.0, A(0)=0.01, d A / d \xi(0)=0.0, d r / d \xi(0)=0.8$

Note that the choice of $d r / d \xi(0)$ is based on the initial cell speed that Jackson measured (roughly 0.8 , as can be observed in Fig. 2). As observed in Fig. 2, the developed model is appeared to predict the transient stall cell speed quite accurately.

Table 1 Jackson (1986) compressor specification

\begin{tabular}{|c|c|c|}
\hline & Rotor & Stator \\
\hline Solidity & 1.43 & 1.1 \\
\hline Chord (mm) & 110 & 114.6 \\
\hline No. of IGVs & \multicolumn{2}{|c|}{0} \\
\hline Tip diameter (mm) & \multicolumn{2}{|c|}{1524} \\
\hline Hub/Tip ratio & \multicolumn{2}{|c|}{0.7} \\
\hline Speed of Rot. (rpm) & \multicolumn{2}{|c|}{500} \\
\hline
\end{tabular}

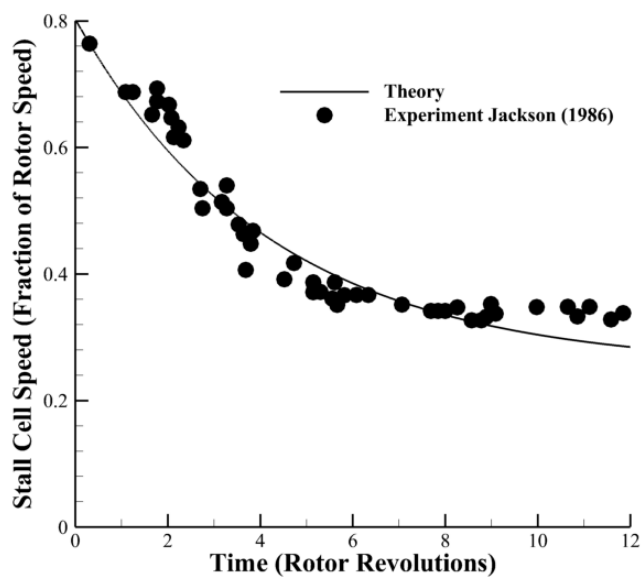

Fig. 2. Transient stall cell speed.

\section{RESULT AND DISCUSSION}

\subsection{Pure Rotating Stall}

In order to investigate the transient behavior of a stall cell, Eqs. (52) and (53) must be solved together. The mean flow coefficient is chosen to be equivalent to 0.25 ( $\Phi=0.25$ ), which was also used by Moore and Greitzer (1986). The initial values and the compression system parameters are: $d \Phi / d \xi(0)=0.0, d A / d \xi(0)=0.0, d r / d \xi(0)=0.6 \quad$ and $B=0.5,1 / a=3.5, l_{c}=8, m=1.75 . \quad$ A comparison between the stall cell amplitude growth calculated from the current model and that calculated from the basic Moore-Greitzer is given in Fig. 3(a). It should be noted that the initial amplitude of the disturbances is assumed to be $A(0)=0.01$. Figure 3(a) shows that with the current model, the rate of the amplitude growth is predicted to be steeper and the fully-developed rotating stall pattern to achieve faster, as compared to the basic Moore-Greitzer. The experimental stall cell amplitudes reported by Garnier et al. (1991) are adapted and compared to the model in Fig. 3(b). As this figure shows, the current model gives a more accurate prediction of the stall cell amplitudes.

Figures 4(a) and 4(b) show the stall cell amplitude growth and it's time derivative for three different values of the initial disturbance amplitudes: $A(0)=0.1,0.01$ and 0.001 . Figure 4(a) suggests that the initial disturbance does not have any effect on the final amplitude of the stall cell. However, the greater the initial amplitude, the faster the fully-developed rotating stall is achieved. Furthermore, Fig. 4(b) shows that the rate of the amplitude growth is the same for different initial amplitudes. 


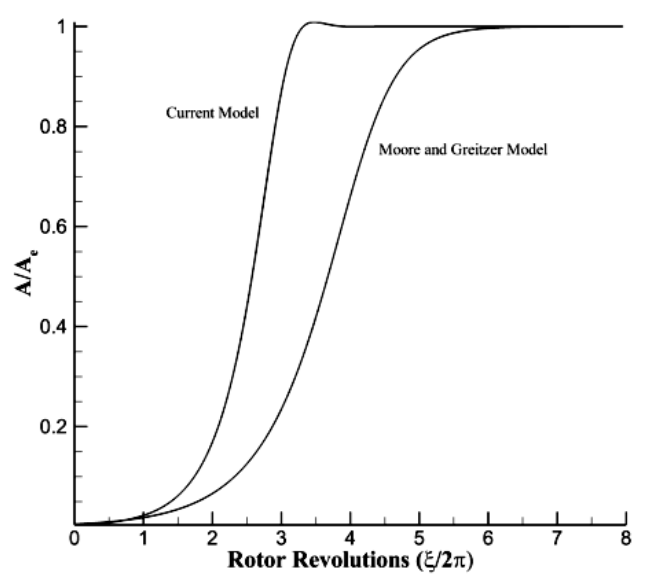

a) Comparison between the current model and Moore-Greitzer

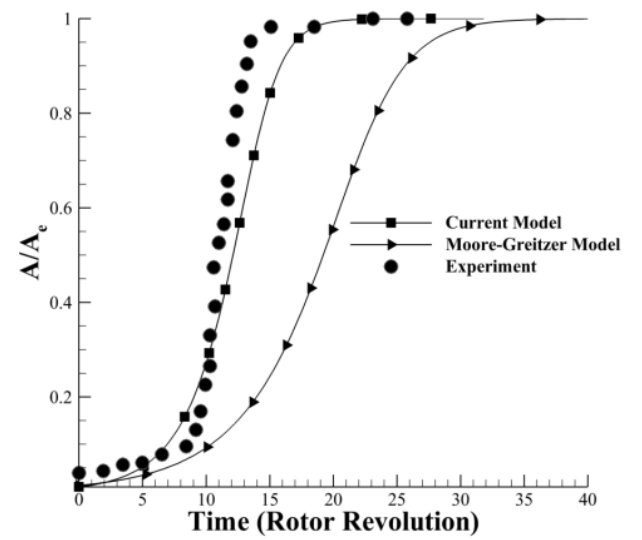

b) Comparison with experiments (Garnier et al. (1991))

Fig. 3. Normalized stall cell amplitude.

As stated by Koff and Greitzer (1984), the positively sloped portion of the compressor characteristic cure does not have any effect on the steady rotating stall speed. Therefore, the positively sloped part was simply faired in between the peak and valley points (see Fig. 1). In order to investigate the effect of the above mentioned portion of the compressor characteristic on the transient performance of the compressor during rotating stall with the current model, the amplitude growth of the stall cell is shown in Fig. 5 for three different slopes $(0.5,1.08$ and 2) at $\Phi=0.25, \Psi=0.38$. It should be noted that the slope which is specified by Eq. (45) at $\Phi=0.25$ is equivalent to 1.08 . Figure 5 shows that the final amplitude of the stall cell is the same for different initial slopes. However, the transient part is different in that a greater slope causes greater stall cell amplitudes.

\subsection{Instability Initiation}

In the above section, only Eqs. (52) and (53) were solved together in order to investigate pure rotating stall. Now, by solving the complete governing Eqs. (50-53), the path into instability and the conditions under which the compression system triggers surge or rotating stall can be studied.

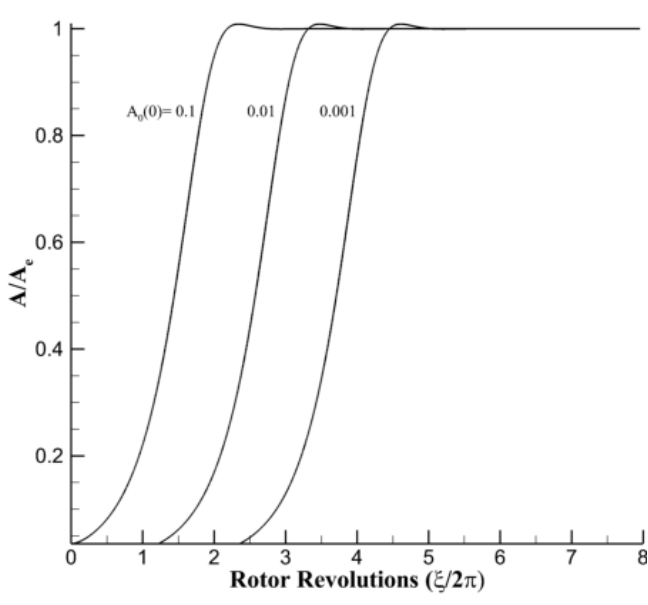

a) Normalized stall cell amplitude

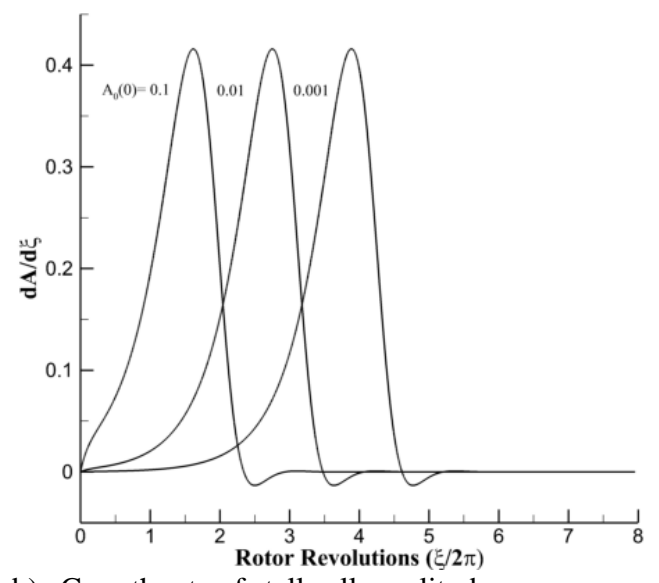

b) Growth rate of stall cell amplitude

Fig. 4. Effect of initial disturbance amplitude on the stall amplitude and its rate.

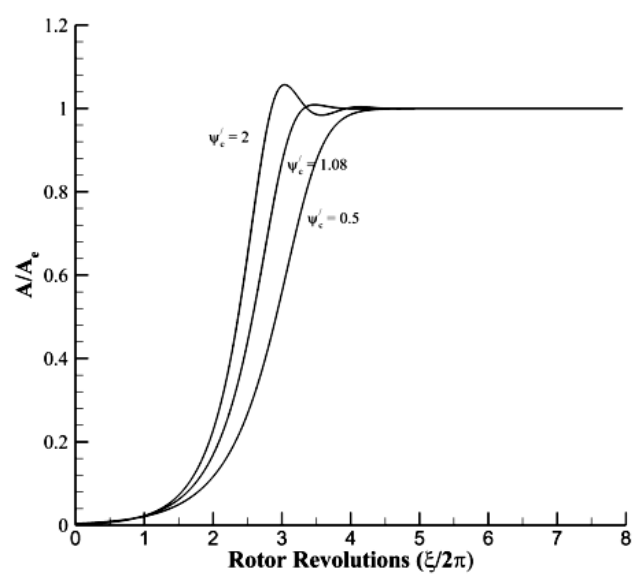

Fig. 5. Effect of the compressor characteristic slope on the stall cell amplitude, $\Phi=0.25$.

\subsubsection{Rotating Stall}

As mentioned earlier, Camp and Day (1997) showed that modal rotating stall occurs near the compressor peak pressure rise, $\psi_{c}^{\prime}=0$ (at a slope of the compressor total to static pressure rise characteristic between roughly -0.2 to +0.2 ). In order to study the effect of initial flow coefficient 
on modal stall inception, the governing equations have been solved at $\Phi=0.55$ (which is in the negative slope portion of the compressor characteristic) for two initial disturbance amplitudes. The initial values and compression system parameters are the same as those used earlier in pure rotating stall. Figure 6(a) and 6(b) show the local and mean flow coefficients for the initial disturbance amplitude equivalent to 0.01 and 0.1 , respectively. As Fig. 6(a) shows, the modal disturbances have not neither grown up nor damped, but remained unchanged (note that if the initial disturbance amplitude were smaller enough, this disturbance would damp). If the initial amplitude of the disturbances increases to 0.1 (Fig. 6(b)), the modal waves grow up and cause the mean flow coefficient to suddenly reduce and the local flow coefficient to have large oscillations leading to a fully developed rotating stall pattern. This suggests that with a negative slope of the characteristic, rotating stall can occur if the initial amplitude of the disturbances is large enough, which confirms the results in Camp and Day (1997). Note that in the Moore-Greitzer model, any negative slope causes the modal disturbances to be damped, regardless of the value of the initial disturbances.

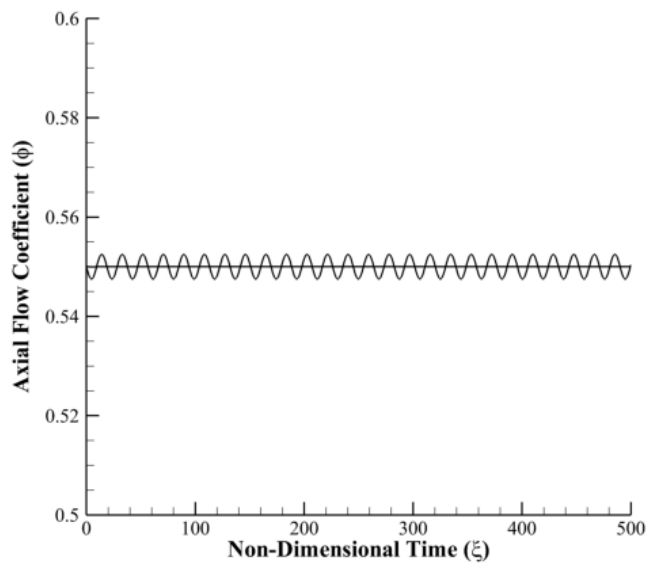

a) $A(0)=0.01$

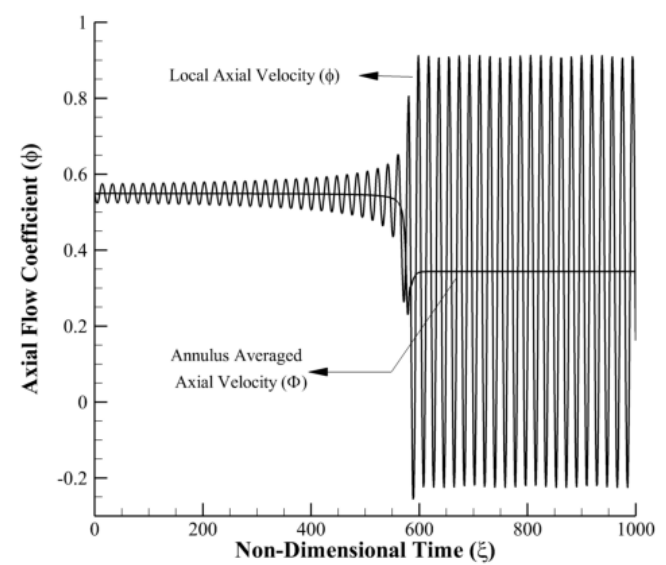

b) $A(0)=0.1$

Fig. 6. Local and annulus-averaged axial velocity coefficient as a function of time, $\Phi=0.55$.
Similar to the negative slope, the governing equations have been solved at $\Phi=0.48$ in the positive slope portion of the characteristic. Figures 7(a) and 7(b) show the local and mean axial flow coefficients for the initial disturbance amplitude equivalent to 0.01 and 0.1 , respectively. As seen, rotating stall is triggered in both cases. The two cases are different in that with a greater initial amplitude, the fully developed condition is achieved faster (Fig. 7(b)). Comparing Fig. 7(b) to Fig. 6(b) shows that if the initial operating point is located in the negative slope portion of the compressor characteristic, the time needed for a steady state stall cell formation is much greater than the positive slope.

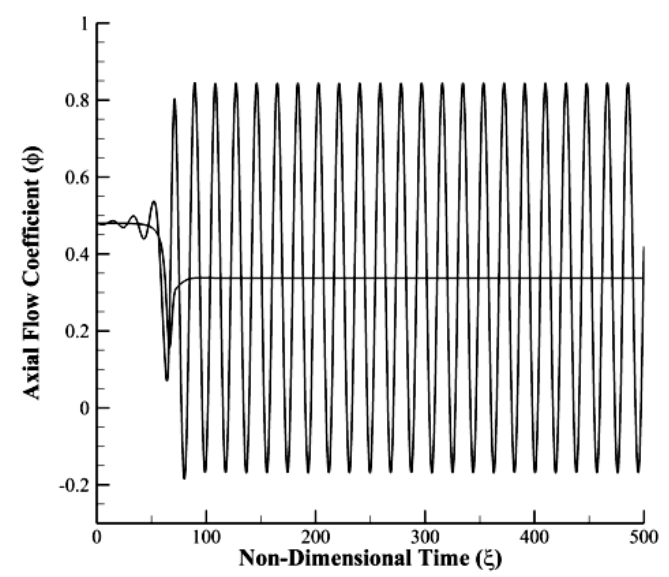

a) $A(0)=0.01$

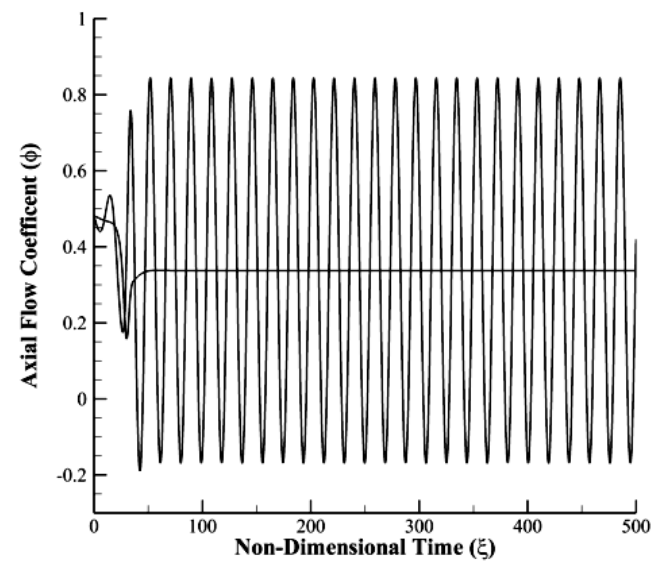

b) $A(0)=0.1$

Fig. 7. Local and annulus-averaged axial velocity coefficient as a function of time, $\Phi=0.48$.

\subsubsection{Surge}

Moore and Greitzer (1986) showed that two parameters (the Greitzer parameter, $B$, and the compressor mean effective length, $l_{c}$ ) determine the type of the instabilities (surge or rotating stall). In order to investigate surge with the current model, $B$ and $l_{c}$ have been chosen to be equivalent to 1.2 and 8 , respectively, for two initial operating points: $\Phi=0.48$ and $\Phi=0.45$. Note further that the initial conditions are: 
$d \Phi / d \xi(0)=0.0, d A / d \xi(0)=0, A(0)=0.01, d r / d \xi(0)=0.0$

. Figure 8 illustrates the variation of the mean axial flow coefficient for the two cases modeled. As this figure shows, deep surge is triggered in both cases (the flow coefficient becomes negative). Although the frequency of the instability is the same for the two initial points, surge is deeper for $\Phi=0.45$.

Figure 9 shows the amplitude of the disturbances as a function of the non-dimensional time. This figure reveals that the disturbances (which identifies the existence of modal waves and rotating stall) first grow up significantly and then become zero (which shows the occurrence of surge). Furthermore, for $\Phi=0.45$, the growth rate of the disturbances is greater, and therefore, it ends up with surge faster.

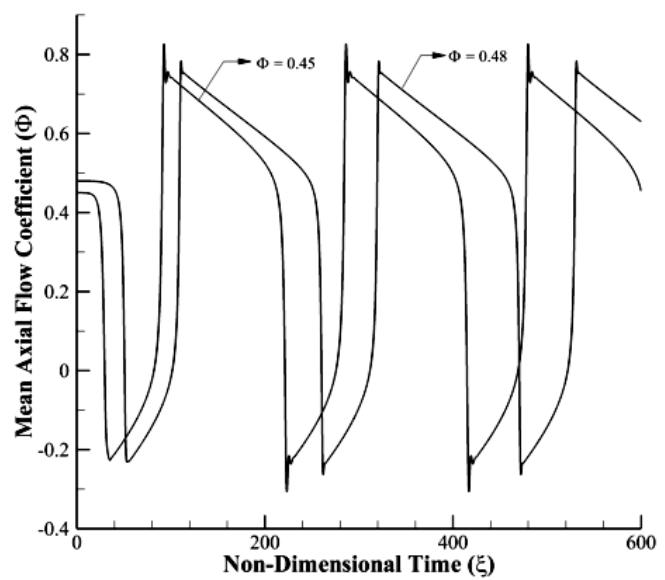

Fig. 8. Annulus-averaged axial velocity coefficient during transient to surge.

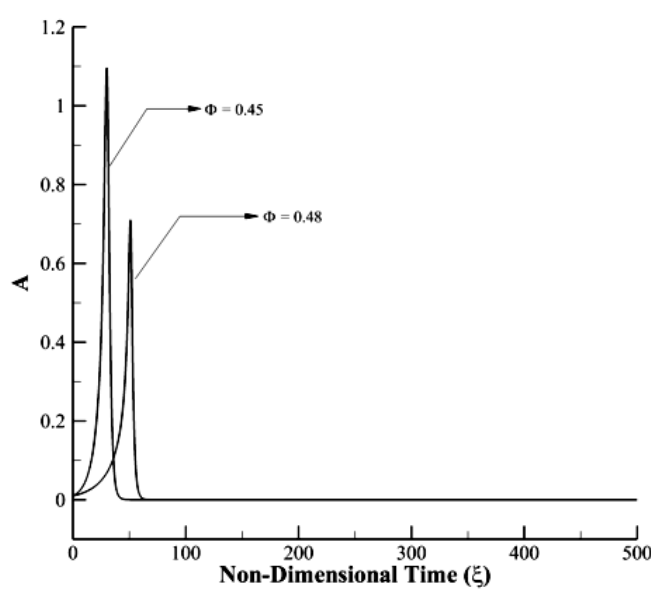

Fig. 9. Disturbance amplitude during transient to surge.

\subsubsection{Effect of Throttle Rate}

One of the capabilities of the current model is that it enables the investigation of the initial $d \Phi / d \xi$, which can be interpreted as the rate of throttling (it has been experimentally investigated by Garnier et al. (1991)). In order to investigate the effect of the throttling rate on the type of the instability, two initial $d \Phi / d \xi$ have been modeled: 0.01 and 0.04 . The initial operating point is at $\Phi=0.48$, which is located at the positive slope portion of the compressor characteristic. It should be noted that $B$ is chosen to be 0.5 , which is less than its critical value (0.8). Therefore, the occurrence of rotating stall is expected. Furthermore, $l_{c}$ is 8 and the initial values are: $d A / d \xi(0)=0, A(0)=0.01, d r / d \xi(0)=0.6$.

Figures 10 and 11 show the time variation of the axial flow coefficient and $d \Phi / d \xi$ for the two cases investigated. In Fig. 10, the mean axial flow coefficient has reached to a constant value, which identifies the occurrence of fullydeveloped rotating stall. By increasing the throttling rate to 0.04 , however, the annulus averaged flow does not remain constant and shows large oscillations, identifying the occurrence of surge. It can be concluded that the rate of throttling can change the type of the instability in a compression system.

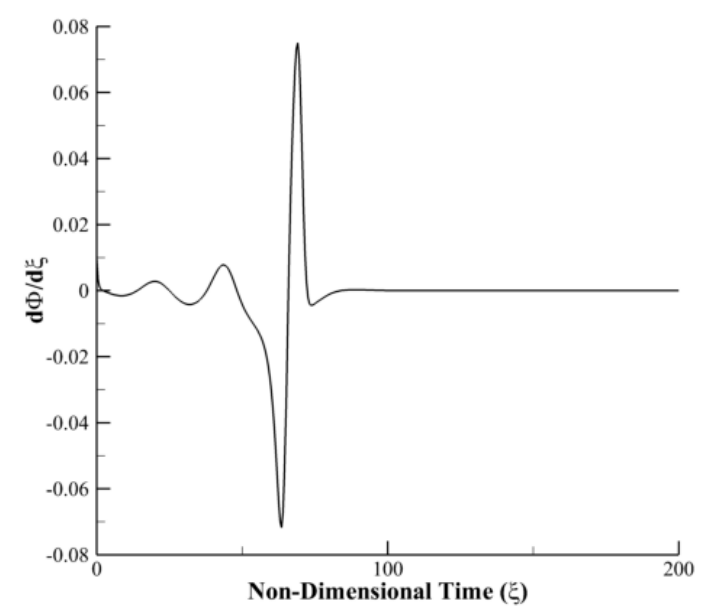

b) $d \Phi / d \xi$

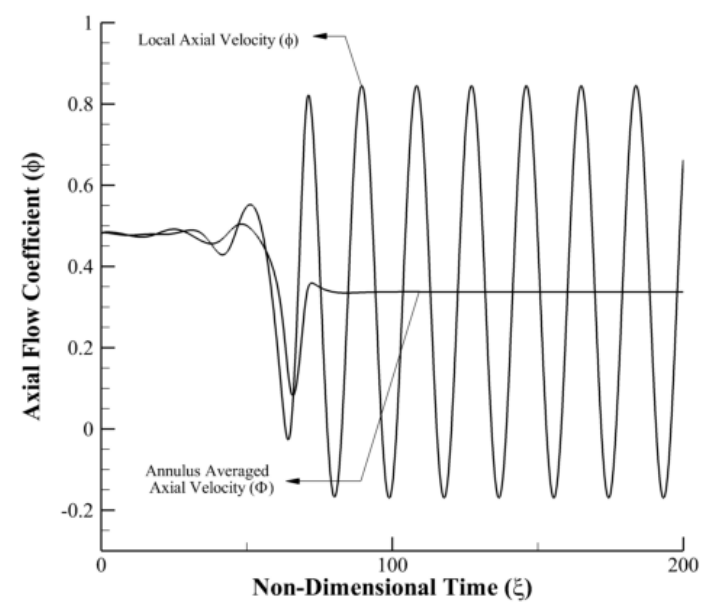

b) Axial flow coefficient

Fig. 10. Local and annulus-averaged axial velocity coefficient as a function of time (initial $d \Phi / d \xi=\mathbf{0 . 0 1})$. 


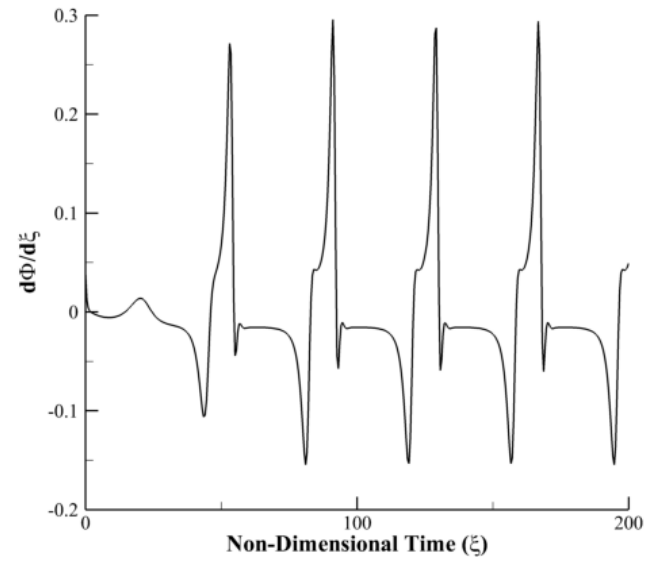

a) $d \Phi / d \xi$

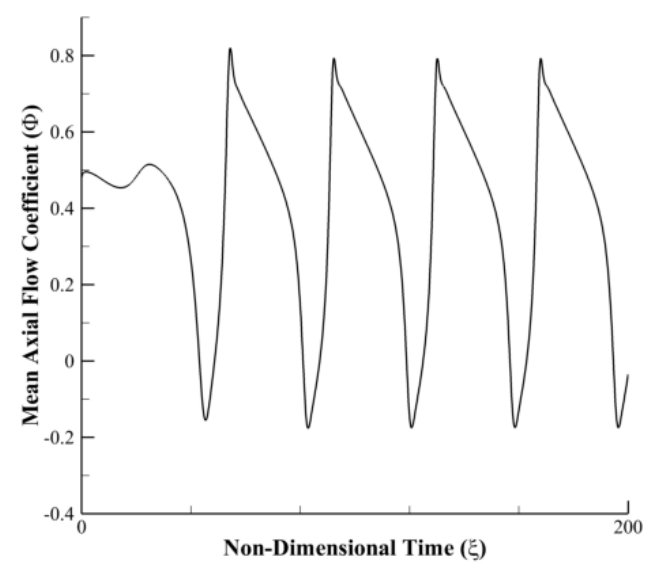

b) Axial flow coefficient

Fig. 11. Local and annulus-averaged axial velocity coefficient as a function of time (initial $d \Phi / d \xi=\mathbf{0 . 0 4})$.

\section{CONClusion}

A new model has been developed by modifying the basic Moore-Greitzer theory. The general assumptions were similar to those of the MooreGreitzer model. However, a second order hysteresis was assumed for the pressure rise of the rotor and stator rows, which added new parameters to the governing equations. The modified model has some advantages and new capabilities, as compared to the basic Moore-Greitzer. One of these advantages is that the governing equations in the current model include the slope of the compressor characteristic curve. It was shown that in the positive slope portion of the compressor characteristic, $\psi_{c}^{\prime}$ does not affect the final stall cell speed and its amplitude. However, the transient stall cell behavior was shown to be different having different slopes. Results further revealed that $\psi_{c}^{\prime}$ changes the fullydeveloped rotating stall characteristic. The effect of the initial amplitude of the disturbance on the stall cell behavior was also investigated in the current study and it was shown that it does not change the stall cell final speed and amplitude. It was shown in the current study that if the initial operating point is located in the negative slope part of the compressor characteristic, the disturbances may be damped, kept unchanged or grown up to fully-developed rotating stall, depending on their initial amplitudes. If the initial point is located in the positive slope part, however, the disturbances were shown to be grown up to rotating stall, regardless of their initial amplitudes. Another finding was that in the positive slope portion, the fully-developed rotating stall is achieved considerably faster, as compared to the negative slope. An advantage of the current model is that it includes the second derivative of the mean axial flow coefficient $\left(d^{2} \Phi / d \xi^{2}\right)$. This enables the investigation of the initial $d \Phi / d \xi$, which can be interpreted as the rate of throttling. It was shown that the rate of throttling can change the type of instability (e.g., rotating stall to surge).

\section{REFERENCES}

Camp, T. R. and I. J. Day (1998). A Study of Spike and Modal Stall Phenomena in a Low-Speed Axial Compressor. Journal of Turbomachinery 120, 393-401.

Chen, J. P., M. D. Hathaway and G. P. Herrick (2008). Prestall behavior of a transonic axial compressor stage via time-accurate numerical simulation. Journal of Turbomachinery 130(4).

Choi, M., M. Vahdati and M. Imregun (2011). Effect of Fan Speed on Rotating Stall Inception and Recovery. Journal of Turbomachinery 133(4).

Cumpsty, N. A. and E. M. Greitzer (1982). A simple model for compressor stall cell propagation. Journal of Eng. Gas Turbines Power 104(1), 170-176.

Day, I. J. (1993a). Active suppression of rotating stall and surge in axial compressors. Journal of Turbomachinery 115(1), 40-47.

Day, I. J. (1993b). Stall inception in axial flow compressors. Journal of Turbomachinery 115(1), 1-9.

Emmons, H. W. (1955). Compressor surge and stall propagation. Trans. of the ASME 77(4), 455467.

Epstein, A. H., J. F. Williams and E. M. Greitzer (1989). Active suppression of aerodynamic instabilities in turbomachines. Journal of Propulsion and Power 5(2), 204-211.

Garnier, V. H., A. H. Epstein and E. M. Greitzer (1991). Rotating waves as a stall inception indication in axial compressors. Journal of Turbomachinery 113(2), 290-301.

Gong, Y. (1999). A computational model for rotating stall and inlet distortions in multistage compressors, Doctoral dissertation, Massachusetts Institute of Technology.

Greitzer, E. M. and F. K. Moore (1986). A theory of post-stall transients in axial compression 
M. Shahriyari et al. / JAFM, Vol. 14, No. 3, pp. 897-908, 2021.

systems: part II-application. Journal of Eng. Gas Turbines Power 108(2), 231-239.

Hendricks, G. J., L. P. Bonnaure, J. P. Longley, E. M. Greitzer and A. H. Epstein (1993). Analysis of rotating stall onset in high speed axial flow compressors. 29th Joint Propulsion Conference and Exhibit.

Jackson, A. D. (1987). Stall cell development in an axial compressor. Journal of Turbomachinery 109(4), 492-498.

Khaleghi, H. (2015). Stall inception and control in a transonic fan, part A: Rotating stall inception. Journal of Aerospace Science and Technology 41, 250-258.

Khaleghi, H., M. J. Shahriyari and M. Heinrich (2020). A theory for rotating stall in contrarotating fans. Proc IMechE, Part C: Journal of Mechanical Engineering Science.

Koff, S. G. and E. M. Greitzer (1984, June). Stalled Flow Performance for Axial Compressors: IAxisymmetric Characteristic. ASME Paper 84GT-93.

McDougall, N. M., N. A. Cumpsty and T. P. Hynes (1990). Stall inception in axial compressors. Journal of Turbomachinery 112(1), 116-123.

Moore, F. K. (1984a). A theory of rotating stall of multistage axial compressors: part I-small disturbances. Journal of Eng. Gas Turbines Power 160(2), 313-320.

Moore, F. K. (1984b). A theory of rotating stall of multistage axial compressors: Part II-Finite disturbances. Journal of Eng. Gas Turbines Power 160(2), 321-326.

Moore, F. K. and E. M. Greitzer (1986). A theory of post-stall transients in axial compression systems: Part I-Development of equations. Journal of Eng. Gas Turbines Power 108(1), 68-76.

Paduano, J. D., A. H. Epstein, L. Valavani, J. P. Longley, E. M. Greitzer and G. R. Guenette (1993). Active control of rotating stall in a low-speed axial compressor. Journal of Turbomachinery 115(1), 48-56.

Righi, M., V. Pachidis, L. Könözsy and L. Pawsey (2018). Three-dimensional through-flow modelling of axial flow compressor rotating stall and surge. Aerospace Science and Technology 78, 271-279.

Shahriyari, M. J., H. Khaleghi and M. Heinrich (2019). A Model for Stall and Surge in LowSpeed Contra-Rotating Fans. Journal of Eng. Gas Turbines Power 141(8).

Stenning, A. H., A. R. Kriebel and S. R. Montgomery (1956). Stall Propagation in axial-flow compressors. NACA-TN-3580.

Takata, H. and S. Nagano (1972). Nonlinear analysis of rotating stall. Journal of Eng. Gas Turbines Power 94(4), 279-293.

Tryfonidis, M., O. Etchevers, J. D. Paduano, A. H. Epstein and G. J. Hendricks (1995). Prestall behavior of several high-speed compressors. Journal of Turbomachinery 117(1), 62-80.

Vo, H. D., C. S. Tan and E. M. Greitzer (2008). Criteria for spike initiated rotating stall. Journal of Turbomachinery 130(1).

Weichert, S. and I. J. Day (2014). Detailed measurements of spike formation in an axia compressor. Journal of Turbomachinery 136(5). 